\title{
Evaluation of chemical-specific lgG antibodies in male workers from a urethane foam factory
}

\author{
Mayumi Tsuji ${ }^{1 *}$, Yasuhiro Ishihara ${ }^{2}$, Toyohi Isse ${ }^{1}$, Chihaya Koriyama ${ }^{3}$, Megumi Yamamoto ${ }^{4}$, Noriaki Kakiuchi ${ }^{5}$, \\ Hsu-Sheng Yu ${ }^{1,6}$, Masayuki Tanaka', Takuto Tsuchiya ${ }^{1}$, Masanori Ohta ${ }^{7}$, Rie Tanaka ${ }^{1}$ and Toshihiro Kawamoto ${ }^{1}$
}

\begin{abstract}
Background: Plastic resins are complex chemicals that contain toluene diisocyanate (TDI) and/or trimellitic anhydride (TMA), which cause occupational allergies (OA), including respiratory allergies. Serum IgGs against TDI and TMA have been suggested as potential markers of the exposure status and as exploring cause of OA. Although TDl-specific lgG has been examined for suspected OA, TMA-specific lgG is not commonly evaluated in a urethane foam factory. This study therefore investigated both TDI- and TMA-specific lgGs in suspected OA patients and to evaluate the usefulness of the measurement of multiple chemical-specific lgG measurement for practical monitoring.
\end{abstract}

Methods: Blood samples were collected from two male workers who developed respiratory allergies supposedly caused by occupational exposure to TDI and/or TMA for the presence of TDI- and TMA-specific lgGs. In addition, blood samples from 75 male workers from a urethane foam factory, along with 87 male control subjects, were collected in 2014 and tested for the same lgGs in 2014. The presence and levels of TDI- and TMA-specific serum IgGs were measured using dot blot assays.

Results: We found that controls had mean concentrations of TDI- and TMA-specific lgGs of 0.98 and $2.10 \mu \mathrm{g} / \mathrm{mL}$, respectively. In the two workers with respiratory allergies, the TDI-specific IgG concentrations were $15.6 \mathrm{and} 9.51 \mathrm{\mu g} /$ $\mathrm{mL}$, and TMA-specific lgG concentrations were 4.56 and $14.4 \mu \mathrm{g} / \mathrm{mL}$, which are clearly higher than those in controls. Mean concentrations of TDI- and TMA-specific lgGs in the factory workers were 1.89 and $2.41 \mathrm{\mu g} / \mathrm{mL}$, respectively, and are significantly higher than those of the controls $(P<0.001$ and $P<0.026$ for TDI- and TMA-specific lgGs, respectively).

Conclusion: The workers suspected of OA showed an evidently high level of TDI- and TMA-specific IgG, and these levels in workers at the urethane foam factory were also significantly higher than those in controls. In conclusion, the measurement of TDI- and TMA-specific lgG among workers using plastic resins is helpful to monitor their exposure status.

Keywords: Chemical-specific lgG antibodies, Occupational allergy (OA), Urethane foam factory, Male workers

\section{Background}

Plastic products are widely used across the society. Most chemicals employed in the production of widely used plastic products and polymers are known to be hazardous to human health [1]. Toluene diisocyanate (TDI), a polymer of polyurethane resin, is a suspected cause of occupational allergies (OAs) in workers exposed to plastic resins

\footnotetext{
* Correspondence: tsuji@med.uoeh-u.ac.jp

${ }^{1}$ Department of Environment Health, University of Occupational and

Environmental Health, Kitakyushu, Japan

Full list of author information is available at the end of the article
}

$[1,2]$. When a worker dealing with TDI develops symptoms of respiratory allergy, OA is often suspected and tested for by examining the levels of TDI-specific immunoglobulin Gs (IgGs) in the patient's blood [3, 4]. As reported by Ye et al., TDI exposure levels are positively correlated with the levels of IgGs against TDI-albumin conjugates in workers handling paints and polishes [5].

Plastic resins are mixtures of chemical substances containing curing agents, catalysts, fire retardants, and surfactants in addition to polymers [6]. Trimellitic anhydride (TMA), which is widely used in many industries, is useful

(c) The Author(s). 2018 Open Access This article is distributed under the terms of the Creative Commons Attribution 4.0 International License (http://creativecommons.org/licenses/by/4.0/), which permits unrestricted use, distribution, and reproduction in any medium, provided you give appropriate credit to the original author(s) and the source, provide a link to the Creative Commons license, and indicate if changes were made. The Creative Commons Public Domain Dedication waiver (http://creativecommons.org/publicdomain/zero/1.0/) applies to the data made available in this article, unless otherwise stated. 
as a curing agent, modifier, plasticizer, and surfactant for epoxy and urethane resins [7-9]. Like TDI, TMA is also known to cause respiratory allergies [10, 11], and TMA-specific IgGs have been detected in workers exposed to this chemical [12].

Since allergen removal is the preferred treatment option for patients with allergic diseases, determining causal allergen (s) is a crucial step in helping these patients. However, in most allergies, it is impossible to identify causal allergens through clinical symptoms alone, as most of these symptoms are not allergen-specific. Therefore, detecting the presence of TDI- and TMA-specific IgGs in serum is a very useful method by which TDI- and TMA-related OAs can be identified. However, as of now, only TDI-specific IgGs are used to test for OAs in workers handling urethane resins $[2,13,14]$. However, since TMA has a possibility to be used in conjunction with TDI in many factories, it is also essential to find a marker that can be employed to identify OAs caused by TMA exposure.

The aim of this study is to investigate the levels of TDI- and TMA-specific IgGs in factory workers from a urethane foam factory, as well as suspected OA patients from this site. We also evaluate the usefulness of measuring the levels of chemical-specific IgGs in practical monitoring the exposure of workers to TDI and TMA.

\section{Methods}

\section{Study subjects}

Subjects suspected of developing $O A$

In May 2014, we identified two male workers who exhibited worsening respiratory symptoms especially while working in the urethane foam factory. One patient (worker A) developed symptoms of rhinitis and coughing, while the other patient (worker B) only developed a cough. Both subjects began showing these allergic symptoms from January 2014.

\section{Urethane foam factory workers}

Blood samples from a total of 75 male workers from a urethane foam factory in Fukuoka, Japan, were obtained for this study in May 2014. The participation rate of workers from this factory was 93\%; a total of 77 workers (including the two subjects suspected of OA) out of 83 workers participated in the study. Six workers refused to participate either because they were ill or because they refused to allow blood collection.

\section{Control subjects}

Blood samples from a total of 87 males under the age of 60 years from Minami-Kyushu City in Japan were collected to serve as controls in July 2014. Among this group, 63 subjects (72\%) were local government employees. Although five subjects $(6 \%)$ in this group were also factory workers, none of these subjects has used or handled plastic resin at the factories.

\section{Detection of chemical-specific lgGs Serum samples}

Approximately $5 \mathrm{~mL}$ of blood was collected from all subjects and centrifuged at $3000 \mathrm{rpm}$ for $10 \mathrm{~min}$ to obtain serum samples.

\section{Detection of chemical-specific lgG by dot blotting}

Levels of chemical-specific IgGs were determined using the dot blot assay which the co-author (TK) has developed and patented [15-17]. In this study, the diagnostic antigens were obtained by mixing human serum albumin (Wako Pure Chemical, Japan.) with the resin precursors TDI (Wako) and TMA (Wako) in a 1:100 ratio at pH 10.8. Details of this procedure have been reported elsewhere [15-17].

\section{Questionnaire survey}

Information on smoking and alcohol consumption and allergic history (asthma, allergic rhinitis, atopic dermatitis, allergic conjunctivitis, and contact dermatitis), as well as usage of plastic resin in daily life was obtained through a self-administered questionnaire. In addition, the two patients suspected of developing OA were interviewed by industrial physicians.

\section{Statistical analyses}

Two-group comparisons were performed using the Mann-Whitney $U$ test or multivariate logistic regression analyses. Three-group comparisons were performed using the Kruskal-Wallis test. We divided the factory workers and controls into three groups (T1-T3), depending on the levels of chemical-specific IgGs detected in controls, and estimated odds ratio (OR) and corresponding 95\% confidence intervals (CIs) after adjusting for the effects of age and allergy history on chemical-specific IgG levels.

All statistical analyses were performed in STATA version 14 (Stata Corp, College Station, TX), and results were considered to be statistically significant at $P<0.05$ (two-sided).

\section{Ethics review}

This study was approved by the Institutional Ethics Committee at the University of Occupational and Environmental Health in 2013 (H25-008) and Kagoshima University Graduate School of Medical and Dental Sciences in 2014 (486). Written informed consents were obtained from all participants.

\section{Results}

Age, lifestyle characteristics, and immunoglobulin profiles of patients suspected of developing $O A$

Table 1 shows age, lifestyle characteristics, and IgG profiles of the two patients suspected of developing OA. Both have worked in the manufacturing department of the urethane foam factory since they were employed. Total IgE, IgG, and 
Table 1 Characteristics and immunoglobulin profiles of the two subjects suspected of developing OA

\begin{tabular}{lll}
\hline & Worker A & Worker B \\
\hline Age (year) & 43 & 52 \\
Employment period (year) & 3 & 27 \\
Smoking habits & No & No \\
Habitual alcohol drinking & No & No \\
Allergic history & Allergic rhinitis & Allergic rhinitis \\
Immunoglobin profile & & \\
TDl-specific $\operatorname{lgG}(\mu \mathrm{g} / \mathrm{mL})$ & 15.62 & 9.51 \\
TMA-specific $\operatorname{lgG}(\mu \mathrm{g} / \mathrm{mL})$ & 4.56 & 14.39 \\
TDI-specific $\operatorname{lgE}(\mathrm{UA} / \mathrm{mL})$ & $\leq 0.34$ & $\leq 0.34$ \\
Total $\operatorname{lgG}(\mathrm{mg} / \mathrm{dL})$ & 1597 & 1180 \\
Total $\lg E(\mathrm{IU} / \mathrm{mL})$ & 29.4 & 106 \\
\hline
\end{tabular}

TDI-specific IgE levels were measured at a commercial company (SRL, Inc. in Japan), though the TMA-specific IgE test was not commercially available.

\section{Characteristics of urethane foam factory workers and control subjects Urethane foam factory workers}

The median, 25th percentile, and 75th percentile of workers' ages were $37.0,31.0$, and 47.0 years, respectively. The percentages of smokers and habitual alcohol drinkers were 48 and 51\%, respectively. In this group, $33 \%$ of the subjects had a history of allergy. The median employment period was 10 (range $=1-35$ ) years.

\section{Control subjects}

The median, 25th percentile, and 75th percentile of control subjects' ages were 49.0, 39.0, and 52.0 years, respectively. The percentage of smokers and habitual alcohol drinkers were 30 and $29 \%$, respectively. In this group, $40 \%$ of the subjects had a history of allergy.

\section{TDI- and TMA-specific IgG concentrations in urethane foam factory workers and controls}

Table 2 shows the distribution of TDI- and TMA-specific IgG concentrations in the workers and controls, along with other factors such as age and lifestyle characteristics. Age had a significant effect on the levels of TDI-specific IgGs in the control group $(P=0.033)$. The median values of IgG in the urethane factory worker and control groups were lower than those of the two patients suspected of developing OA. However, there were some workers, and even some controls who had higher TDI- and TMA-specific IgG levels than the two patients, suspected of having developed OA.

There were no workers who used plastic resin in daily life, but there was only one control who used plastic
Table 2 TDI- and TMA-specific lgG concentrations in urethane foam factory workers and controls

\begin{tabular}{|c|c|c|c|c|c|c|c|}
\hline \multicolumn{8}{|c|}{ Geometric mean of lgG $(95 \% \mathrm{Cl})(\mu \mathrm{g} / \mathrm{mL})$} \\
\hline \multicolumn{4}{|l|}{ Controls } & \multicolumn{4}{|c|}{ Urethane foam factory workers } \\
\hline \multicolumn{2}{|l|}{$\begin{array}{l}\text { Number for } \\
\text { TDI (TMA) }\end{array}$} & TDI & TMA & Number & TDI & TMA & $P$ value* \\
\hline \multicolumn{2}{|l|}{$\begin{array}{l}\text { Median of } \\
\text { lgG (range) }\end{array}$} & $\begin{array}{l}0.81 \\
(\mathrm{ND}- \\
12.9)\end{array}$ & $\begin{array}{l}1.77 \\
\text { (ND- } \\
36.8)\end{array}$ & & $\begin{array}{l}2.07 \\
(\mathrm{ND}- \\
29.1)\end{array}$ & $\begin{array}{l}2.58 \\
(\mathrm{ND}- \\
74.6)\end{array}$ & $\begin{array}{l}<0.001 \\
\text { (TDI) } 0.026 \\
\text { (TMA) }\end{array}$ \\
\hline \multicolumn{8}{|l|}{ Age (years) } \\
\hline $\begin{array}{l}\text { Below } \\
39\end{array}$ & $\begin{array}{l}23 \\
(23)\end{array}$ & $\begin{array}{l}1.22 \\
(0.75 \\
1.98)\end{array}$ & $\begin{array}{l}3.26 \\
(2.09 \\
5.08)\end{array}$ & 44 & $\begin{array}{l}1.69 \\
(1.10 \\
2.59)\end{array}$ & $\begin{array}{l}2.44 \\
(1.46 \\
4.07)\end{array}$ & \\
\hline $40-49$ & $\begin{array}{l}23 \\
(22)\end{array}$ & $\begin{array}{l}1.41 \\
(0.91 \\
2.18)\end{array}$ & $\begin{array}{l}1.46 \\
(0.64 \\
3.32)\end{array}$ & 19 & $\begin{array}{l}1.91 \\
(0.94 \\
3.86)\end{array}$ & $\begin{array}{l}2.33 \\
(1.07 \\
5.08)\end{array}$ & \\
\hline $\begin{array}{l}50 \text { and } \\
\text { above }\end{array}$ & $\begin{array}{l}41 \\
(40)\end{array}$ & $\begin{array}{l}0.64 \\
(0.35 \\
1.20)\end{array}$ & $\begin{array}{l}1.92 \\
(1.26 \\
2.93)\end{array}$ & 12 & $\begin{array}{l}2.82 \\
(1.47 \\
5.42)\end{array}$ & $\begin{array}{l}2.41 \\
(0.94 \\
6.19)\end{array}$ & \\
\hline \multicolumn{2}{|l|}{$P$ value ${ }^{\#}$} & 0.033 & 0.173 & & 0.341 & 0.451 & \\
\hline \multicolumn{2}{|c|}{ Median (25 and } & \multicolumn{2}{|c|}{$37(31,47)$} & & $49(3$ & 52) & $<0.001$ \\
\hline
\end{tabular}

75 percentile)

Allergic history

\begin{tabular}{|c|c|c|c|c|c|c|}
\hline No & $\begin{array}{l}49 \\
\text { (48) }\end{array}$ & $\begin{array}{l}1.19 \\
(0.89 \\
1.61)\end{array}$ & $\begin{array}{l}2.01 \\
(1.39 \\
2.91)\end{array}$ & 50 & $\begin{array}{l}1.95 \\
(1.33 \\
2.85)\end{array}$ & $\begin{array}{l}2.24 \\
(1.36 \\
3.71)\end{array}$ \\
\hline Yes & $\begin{array}{l}38 \\
(37)\end{array}$ & $\begin{array}{l}0.75 \\
(0.40 \\
1.42)\end{array}$ & $\begin{array}{l}2.22 \\
(1.29 \\
3.80)\end{array}$ & 25 & $\begin{array}{l}1.79 \\
(1.00 \\
3.20)\end{array}$ & $\begin{array}{l}2.78 \\
(1.64 \\
4.71)\end{array}$ \\
\hline$P$ value & & 0.686 & 0.716 & & 0.800 & 757 \\
\hline \multicolumn{7}{|c|}{ Smoking habit** } \\
\hline No & $\begin{array}{l}61 \\
(60)\end{array}$ & $\begin{array}{l}0.95 \\
(0.70, \\
1.29)\end{array}$ & $\begin{array}{l}1.83 \\
(1.23 \\
2.71)\end{array}$ & 39 & $\begin{array}{l}1.76 \\
(1.09 \\
2.82)\end{array}$ & $\begin{array}{l}2.12 \\
(1.35 \\
3.34)\end{array}$ \\
\hline Yes & $\begin{array}{l}26 \\
(25)\end{array}$ & $\begin{array}{l}1.06 \\
(0.46 \\
2.47)\end{array}$ & $\begin{array}{l}2.90 \\
(1.87 \\
4.49)\end{array}$ & 36 & $\begin{array}{l}2.07 \\
(1.38 \\
3.12)\end{array}$ & $\begin{array}{l}2.75 \\
(1.48 \\
5.12)\end{array}$ \\
\hline value & & 0.496 & 0.195 & & 0.668 & 331 \\
\hline
\end{tabular}

Habitual alcohol

drinking**

\begin{tabular}{|c|c|c|c|c|c|c|}
\hline No & $\begin{array}{l}62 \\
(61)\end{array}$ & $\begin{array}{l}0.90 \\
(0.58, \\
1.39)\end{array}$ & $\begin{array}{l}2.15 \\
(1.47, \\
3.14)\end{array}$ & 37 & $\begin{array}{l}1.80 \\
(1.05, \\
3.06)\end{array}$ & $\begin{array}{l}3.24 \\
(2.02, \\
5.20)\end{array}$ \\
\hline Yes & $\begin{array}{l}25 \\
(24)\end{array}$ & $\begin{array}{l}1.19 \\
(0.83 \\
1.71)\end{array}$ & $\begin{array}{l}1.99 \\
(1.16 \\
3.43)\end{array}$ & 38 & $\begin{array}{l}2.00 \\
(1.41 \\
2.84)\end{array}$ & $\begin{array}{l}1.82 \\
(1.02, \\
3.24)\end{array}$ \\
\hline$P$ value & & 0.262 & 0.577 & & 0.678 & 0.145 \\
\hline
\end{tabular}

$N D$ not detected

${ }^{\#} P$ values were obtained using Kruskal-Wallis test

${ }^{\$} P$ values were obtained using Mann-Whitney $U$ test

${ }^{*} P$ values were calculated for the comparison between controls and factory workers by Mann-Whitney $U$ test

**P values were less than 0.05 in comparison of the prevalence of smokers and alcohol drinkers between controls and factory workers 
resin in daily life. However, TDI- and TMA-specific IgGs were not detected in this control.

\section{Differences in the distribution of TDI- and TMA-specific IgG levels between urethane foam factory workers and controls}

Among the control group, the geometric means of TDI- and TMA-specific IgGs were $0.98 \mu \mathrm{g} / \mathrm{mL}(0.72$, 1.34; $95 \% \mathrm{CI})$ and $2.10 \mu \mathrm{g} / \mathrm{mL}(1.55,2.84 ; 95 \% \mathrm{CI})$, respectively. TMA-specific IgG could not be measured for the two control subjects because of the shortage of the antigen whose antigenicity should be identical with that used for workers' IgG measurement. The geometric means of TDI- and TMA-specific IgGs for the urethane foam factory workers were $1.89 \mu \mathrm{g} / \mathrm{mL}$ $(1.39,2.59,95 \% \mathrm{CI})$ and $2.41 \mu \mathrm{g} / \mathrm{mL}(1.66,3.50 ; 95 \%$ $\mathrm{CI}$ ), respectively. The mean concentrations of TDIand TMA-specific IgGs in the factory workers were significantly higher than those of controls $(P<0.001$ and $P=0.026$, respectively) by Mann-Whitney $U$ test (Fig. 1).

The geometric means of TDI- and TMA-specific IgGs for controls were $0.98 \mu \mathrm{g} / \mathrm{mL}$ (95\% CI 0.72, $1.34)$ and $2.10 \mu \mathrm{g} / \mathrm{mL}(95 \% \mathrm{CI} 1.55,2.84)$, respectively. The geometric means of TDI- and TMA-specific IgGs for the urethane foam factory workers were $1.89 \mu \mathrm{g} / \mathrm{mL}(95 \% \mathrm{CI}: 1.39,2.59)$ and $2.41 \mu \mathrm{g} / \mathrm{mL}$ (95\% CI: 1.66, 3.50), respectively. The mean concentrations of TDI- and TMA-specific IgGs in the factory workers were significantly higher than those of controls $(P<0.001$ and $P=0.026$, respectively) as determined by Mann-Whitney $U$ test.

Logistic regression analyses also show that the prevalence of factory workers in the T3 category in the TDI-specific IgG group was significantly higher than that of controls (OR 2.71; 95\% CI 1.22, 6.04) (Table 3), indicating that more factory workers had high levels of
TDI-specific IgG than controls. Although the number of factory workers having high values of TMA-specific IgGs was also more than those of controls, this difference was not found to be significant.

\section{Discussion}

This study reveals that workers who handle plastic resins in urethane foam factories are likely to have significantly higher levels of TDI- and TMA-specific IgGs in their blood serum than in control subjects who do not handle plastic resins. Furthermore, we find that workers who develop OAs have higher TDIand TMA-specific IgGs than controls. These findings indicate that measuring the levels of chemical-specific IgGs may be helpful in evaluating if workers handling plastic resins have been exposed to TDI and TMA, and if they have developed OAs against these chemicals.

In this study, two workers (labeled A and B), who developed clinical symptoms of $\mathrm{OA}$, were found to have high levels of TDI- and TMA-specific IgGs. According to an interview with industrial physicians, some of the workers might not wear a protective equipment properly, which could affect the exposure level for each worker. However, these workers' IgG levels were not always higher than those observed in other workers without OA symptoms; furthermore, a few samples from the control group also have high levels of TDI- and TMA-specific IgGs. These findings indicate that there can be a lot of variation in an individual's susceptibility to OA and that, although high levels of TDI- and TMA-specific IgGs may serve as indicators of chemical exposure, they may not be very accurate diagnostic indicators of OA development. In addition, due to wide variations in the levels of TDI- and TMA-specific IgGs among individuals, monitoring each factory worker individually over different periods of time with reference to
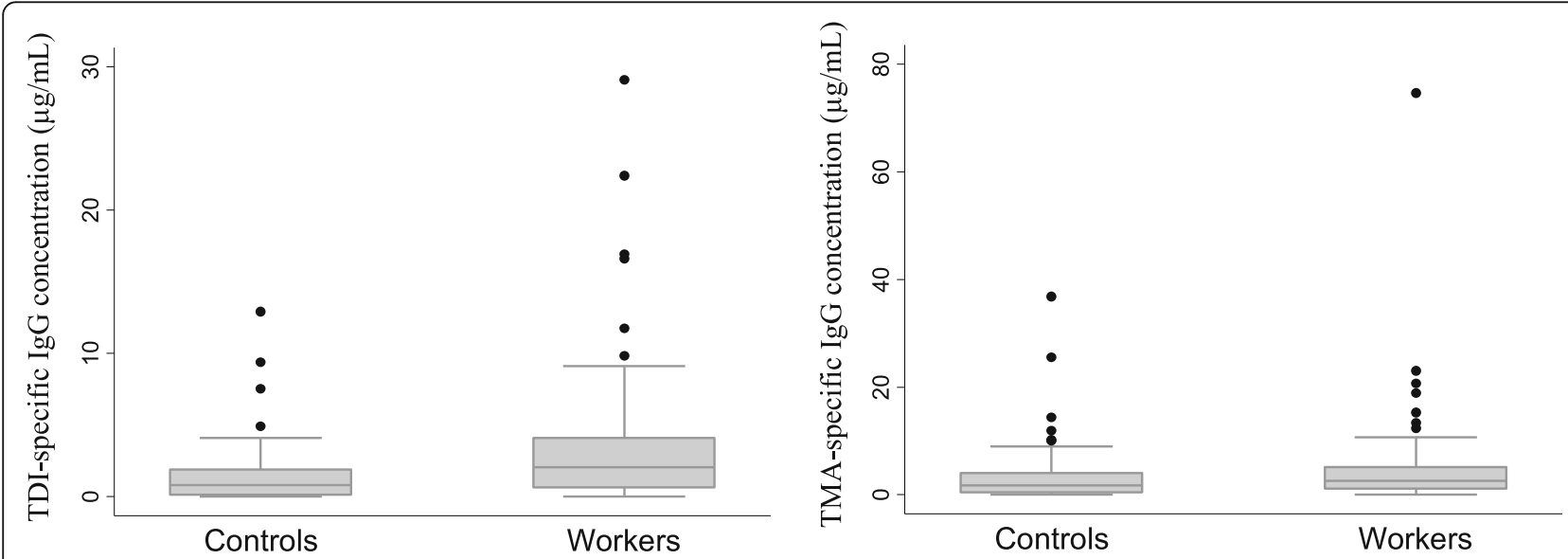

Fig. 1 The distribution of TDI- and TMA-specific lgGs in the urethane foam factory workers and controls 
Table 3 The comparison of TDI- and TMA-specific lgGs between the urethane foam factory workers and controls

\begin{tabular}{lllll}
\hline $\begin{array}{l}\text { Concentration of } \\
\text { specific lgG }\end{array}$ & Controls & Workers & OR $(95 \% \mathrm{Cl})$ & $P$ value $^{\dagger}$ \\
\hline TDI $(\mu \mathrm{g} / \mathrm{mL})$ & $N=87$ & $N=75$ & & \\
T1 $(<0.47)$ & 29 & 16 & 1.00 (reference) & \\
T2 $(\geq 0.47<1.28)$ & 29 & 12 & $0.71(0.27-1.84)$ & 0.479 \\
T3 $(\geq 1.28)$ & 29 & 47 & $2.71(1.22-6.04)$ & 0.015 \\
& & & $P$ for trend $=0.002$ & \\
TMA $(\mu \mathrm{g} / \mathrm{mL})$ & $N=85$ & $N=75$ & & \\
T1 $(<1.00)$ & 28 & 14 & 1.00 (reference) & \\
T2 $(\geq 1.00<3.00)$ & 28 & 24 & $1.50(0.62-3.60)$ & 0.369 \\
T3 $(\geq 3.00)$ & 29 & 37 & $2.14(0.92-4.98)$ & 0.078 \\
& & & $P$ for trend $=0.060$ & \\
\hline
\end{tabular}

${ }^{\dagger} \mathrm{OR}, 95 \% \mathrm{Cl}$, and $P$ values were obtained using multivariate logistic regression analysis adjusted for the effects of age and allergic history

${ }^{\ddagger}$ Concentration of specific lgGs were divided into three groups (T1-T3)

depending on the levels of chemical-specific IgGs detected in controls

the Japanese Guidelines for Diagnosis and Management of Occupational Allergic Diseases (2016) may be necessary for OA diagnosis. In addition, personal monitoring of chemical-specific IgG will be helpful to evaluate the individual exposure status after the employment.

In order to reduce the symptoms or prevent the development of OA, prompt evaluations of a worker's exposure status to possible allergens are crucial. Since workers handling urethane resins are likely to be exposed to many chemical allergens, monitoring the levels of multiple chemical-specific IgGs in their blood simultaneously is a practical and efficient method to keep track of their exposure status to various chemicals. The dot blot assay used in this study is a very practical technique with which multiple chemical-specific IgGs can be evaluated simultaneously in a short period of time.

In this factory, TDI concentration has never exceeded the recommended occupational exposure levels $(0.005 \mathrm{ppm})$ [18] for the last decade. Since the factory is under no legal obligation to measure or maintain TMA levels, there were no records for TMA concentrations within the factory premises. According to the report by Ghosh et. al [12], TMA-specific IgG is useful not only as an indicator of exposure but also as a predictor of subsequent onset of $\mathrm{OA}$ when a high TMA-specific IgG is detected. In this study, one factory worker, without allergic symptoms, showed a high level of TMA-specific IgG $(74.6 \mu \mathrm{g} / \mathrm{mL})$, indicating at a potential risk of $\mathrm{OA}$. The detailed monitoring of the levels of both TDI and TMA will be important and necessary to maintain occupational health.

There are some limitations in our study. First, our study also found that TDI- and TMA-specific IgGs could be present in the control group, who were recruited from Minami-Kyushu City in Japan; this is in agreement with several studies that report the occurrence of chemical-specific IgGs in the general population $[5,19,20]$. Therefore, for employees already showing high chemical-specific IgG levels before occupational exposure, special considerations are required including job assignment with no/low chemical exposure and regular monitoring of chemical-specific IgG. Second, there are no defined cut-off points of TDI- and TMA-specific IgGs for diagnosis of OA and exposure. Further studies are required to understand the clinical significance of these findings.

\section{Conclusion}

The workers suspected of OA showed an evidently high level of TDI- and TMA-specific IgG, and these levels among workers at the urethane foam factory were also significantly higher than those in controls. In conclusion, the measurement of TDI- and TMA-specific IgG levels among workers handling plastic resins maybe helpful in monitoring their exposure status.

\section{Abbreviations \\ OA: Occupational allergy; TDI: Toluene diisocyanate; TMA: Trimellitic anhydride}

\section{Acknowledgements}

We would also like to thank Editage (https://www.editage.jp) for English language editing.

\section{Funding}

This study was funded by an Industrial Disease Clinical Research Grant (grant number 14040101-02 to M.T.) and the JSPS KAKENHI (grant numbers 22790546 and 25860472 to M.T.).

\section{Availability of data and materials}

Please contact the authors with requests for data.

\section{Author's contributions}

$M T, Y I, T I, C K, N K, T T, M O$, and TK contributed to the conception of the study. $M T, Y I$, and MY performed the statistical analyses and wrote the manuscript. MT, TI, CK, HY, MT, RT, and TK contributed to the experimental design and recruitment. All authors have read and approved the final manuscript.

\section{Competing interest}

The authors declare that they have no competing interests.

\section{Ethics approval and consent to participate}

This study was approved by the Institutional Ethics Committee at the University of Occupational and Environmental Health in 2013 (H25-008) and Kagoshima University Graduate School of Medical and Dental Sciences in 2014 (486).

Consent for publication

Written informed consents were obtained from all participants.

\section{Publisher's Note}

Springer Nature remains neutral with regard to jurisdictional claims in published maps and institutional affiliations.

\section{Author details}

${ }^{1}$ Department of Environment Health, University of Occupational and Environmental Health, Kitakyushu, Japan. ${ }^{2}$ Laboratory of Molecular Brain 
Science, Graduate School of Integrated Arts and Sciences, Hiroshima University, Higashihiroshima, Japan. ${ }^{3}$ Department of Epidemiology and Preventive Medicine, Kagoshima University Graduate School of Medical and Dental Sciences, Kagoshima, Japan. ${ }^{4}$ Department of Environment and Public Health, National Institute for Minamata Disease, Minamata, Japan. ${ }^{5}$ Institute of industrial and Ecological Sciences, University of occupational and Environmental Health, Kitakyushu, Japan. ${ }^{6}$ Department of Food Science, College of Agriculture, National Pingtung University of Science and Technology, Pingtung, Taiwan, Republic Of China. 'Department of Food and Health Sciences, International College of Arts and Sciences, Fukuoka Women's University, Fukuoka, Japan.

Received: 30 March 2018 Accepted: 29 May 2018

Published online: 19 June 2018

\section{References}

1. Lithner D, Larsson A, Dave G. Environmental and health hazard ranking and assessment of plastic polymers based on chemical composition. Sci Total Environ. 2011:409(18):3309-24.

2. Swierczynska-Machura D, Brzeznicki S, Nowakowska-Swirta E, Walusiak Skorupa J, Wittczak T, Dudek W, et al. Occupational exposure to diisocyanates in polyurethane foam factory workers. Int J Occup Med Environ Health. 2015;28(6):985-98.

3. Park HS, Kim HY, Nahm DH, Son JW, Kim YY. Specific lgG, but not specific IgE, antibodies to toluene diisocyanate-human serum albumin conjugate are associated with toluene diisocyanate bronchoprovocation test results. J Allergy Clin Immunol. 1999;104(4 Pt 1):847-51.

4. le Pham D, Kim MA, Yoon MG, Lee SI, Shin YS, Park HS. Serum specific IgG response to toluene diisocyanate-tissue transglutaminase conjugate in toluene diisocyanate-induced occupational asthmatics. Annals of allergy, asthma \& immunology : official publication of the American College of Allergy, Asthma, \& Immunology. 2014;113(1):48-54.

5. Ye YM, Kim CW, Kim HR, Kim HM, Suh CH, Nahm DH, et al. Biophysical determinants of toluene diisocyanate antigenicity associated with exposure and asthma. J Allergy Clin Immunol. 2006;118(4):885-91.

6. Ulrich H. Urethane polymers. Published online: 16 JUN 2006. In: Kirk-Othmer encyclopedia of chemical technology. https://doi.org/10.1002/0471238961. 2118052021121809.a01.pub2.

7. Chai OH, Lee HK, Lee YC, Lee MS, Han EH, Kim HT, et al. Roles of TNF-alpha and $\lg E$ in the late phase of contact hypersensitivity induced by trimellitic anhydride. Exp Mol Med. 2005;37(5):408-17.

8. Unosaka K, Watanabe M, Ohtsuka H. Soft polyurethane foam and its uses. Japan patent JP2005-206780A (2005.8.4).(in Japanese).

9. Yamamoto T, Muragaki K, Kawano S. Process for producing trimellitic anhydride phenyl esters. in Japanese: Japan patent WO2011158928 A1 (2011.12.22.

10. Grammer LC, Ditto AM, Tripathi A, Harris KE. Prevalence and onset of rhinitis and conjunctivitis in subjects with occupational asthma caused by trimellitic anhydride (TMA). J Occup Environ Med. 2002;44(12):1179-81.

11. Zhang XD, Andrew ME, Hubbs AF, Siegel PD. Airway responses in Brown Norway rats following inhalation sensitization and challenge with trimellitic anhydride. Toxicological sciences : an official journal of the Society of Toxicology. 2006;94(2):322-9.

12. Ghosh D, Clay C, Bernstein JA. The utility of monitoring trimellitic anhydride (TMA)-specific lgG to predict lgE-mediated sensitization in an immunosurveillance program. Allergy. 2017;1-9.

13. Taniwaki H, Shima S, Tachikawa S, Kato Y, Yoshida T, Ito T, et al. A study on the immunologic effects in workers exposed to low levels of toluene-diisocyanate (TDI). Sangyo igaku Japanese journal of Ind Health. 1987;29(2):130-5.

14. Gui W, Wisnewski AV, Neamtiu I, Gurzau E, Sparer JA, Stowe MH, et al. Inception cohort study of workers exposed to toluene diisocyanate at a polyurethane foam factory: initial one-year follow-up. Am J Ind Med. 2014; 57(11):1207-15.

15. Kawamoto T, Yoshida Y, Isse T. Method for detecting exposure to synthetic resin raw material monomer or synthetic resin precursor: Japan patent. JP5757519B2 (2015.7.29. in Japanese

16. Kawamoto T, Tsuji M, Isse T. Comparison of IgG against plastic resin in workers with and without chemical dermatitis. BMC Public Health. 2015;15:930.

17. Tsuji M, Yu H, Ishihara Y, Isse T, Ikeda-Ishihara N, Tuchiya T, et al. A simple method for detection of multiple chemical-specific lgGs in serum based on dot blotting. Health. 2016;8:1645-53.
18. Recommendation of occupational exposure limits (2017-2018). J Occup Health. 2017:59(5):436-69.

19. Japan Society for Occupational Health. Recommendation such as allowable exposure limit. J Occup Health. 2015;57(4):196-9. (in Japanese)

20. Park HS, Lee SK, Lee YM, Kim SS, Nahm DH. Longitudinal study of specific antibodies to toluene diisocyanate (TDI)-human serum albumin (HSA) conjugate in patients with TDI-induced asthma. The Korean J Intern Med. 2002;17(4):249-51

\section{Ready to submit your research? Choose BMC and benefit from:}

- fast, convenient online submission

- thorough peer review by experienced researchers in your field

- rapid publication on acceptance

- support for research data, including large and complex data types

- gold Open Access which fosters wider collaboration and increased citations

- maximum visibility for your research: over $100 \mathrm{M}$ website views per year

At BMC, research is always in progress.

Learn more biomedcentral.com/submissions 